\title{
Information and Communication Technologies' (ICTs) Enhancing Teaching and Learning in ODL
}

\author{
Constance Kadada ${ }^{1} \&$ Thembinkosi Tshabalala ${ }^{2}$
}

${ }^{1}$ Materials Development Unit, Zimbabwe Open University, Harare, Zimbabwe

${ }^{2}$ Faculty of Arts and Education, Zimbabwe Open University, Harare, Zimbabwe

Correspondence: Constance Kadada, Zimbabwe Open University, Harare, Zimbabwe.

Email: ckadada0@gmail.com

doi: 10.23918/ijsses.v6i2p14

\begin{abstract}
Information and Communication Technologies (ICTs) are digital tools that distribute educational content, and facilitate teaching and learning in ODL (Open and Distance Learning) universities. This study was conducted at the Zimbabwe Open University (ZOU) to ascertain the role that ICTs play in teaching and learning. The qualitative approach was employed and data were gathered through interviews and open-ended questionnaires from nine ZOU staff members and students. It was established that ICTs were used by most students studying with ZOU in the eleven regions and most got their modules as hard copies and through an online platform called MyVista. and they had the option to download and print them. ICTs were used by the students to apply online, register online and get their assignments and results online. It was also discovered that some ZOU academic staff and students did not fully appreciate the importance of ICTs, hence, the need to train them in use of ICTS.
\end{abstract}

Keywords: Information and Communication Technologies, Open and Distance Learning, Teaching and Learning, Enhance

\section{Introduction}

With the advancement of information and communication technologies (ICTs), there is a shift in the way provision of educational materials is done. Arinto (2013) says the role of teachers in the design of pedagogically effective learning environments receives renewed emphasis where ODL course designs are increasingly resource-based, that is, feature online learning activities are organised around web-based resources. In some cases, these are integrated or online discussion-based. The course contents are "more fluid and dynamic" because they are created during synchronous and asynchronous online collaborative activities (Mason, 1998 as cited in Arinto, 2013, p. 168). As new courses are being developed under a resource-based course development contract, developers are encouraged to supplement the print modules (or replace them altogether, if warranted) with online courses including open educational resources (OERs). Course developers can also "integrate online discussion forums, and they are free to use open source web tools, such as blog sites, media sharing sites, and web-based conferencing applications, to enhance course delivery" (Arinto, p. 168). OERs are made possible by ICTs, especially the World Wide Web that allows people to manipulate and share them (Wiley, Bliss \& McEwen, 2014; Smith \& Casserly, 2006). Mishra (2015) takes a step further as she realises that older forms of ICTs can be replaced with massive open online courses (MOOCs) and their applicability to poorer nations. These store large amounts of data, engage students, enhance performance, provide feedback and facilitate interaction between teachers and students. Further, ICTs also use Skype (Mishra, 2015). 
Zimbabwe Open University (ZOU) is an Open and Distance Learning institution that was opened in 1999. It provides distance teaching and learning to students in its ten regions in various parts of the country and to those in the eleventh region, the Virtual Region through the learning resource the module. Mafa and Mpofu (2013) say most students reside in places that are far away from these campuses which poses a challenge for them to visit them regularly. Teaching and learning at ZOU could be enhanced through ICTs and the Internet. The extent to which ZOU uses ICTs in teaching and learning is not well articulated.

\section{Purpose of the Study}

The purpose that this study sought to understand was the extent to which Information and Communication Technologies (ICTs) enhanced teaching and learning to students at the Zimbabwe Open University (ZOU).

\section{Research Questions}

The study sought to answer the following research questions:

1. What impact can ICTs have on teaching and learning at ZOU?

2. Does ZOU have the infrastructure to offer teaching and learning through ICTs to its students?

3. What challenges could ZOU face in a bid to provide ICTs on teaching and learning?

4. What mechanisms could ZOU put in place to fully utilise ICTs in teaching and learning?

\section{Review of Literature}

Zuppo (2012, p. 13) posits that ICTs are used in a diverse manner depending on the context, "however, the primary definition of information and communication technologies revolves around the devices and infrastructures that facilitate the transfer of information through digital means." Awadhiya, Miglani and Gowthaman (2014) acknowledge the use of ICTs in open universities worldwide. In India, though use of ICTs is not evenly distributed, in Awadhiya's et al. (2014) study, they found that most distance learners in India access the Internet through laptops, desktops and smartphones. Through use of ICTs, higher education is promoted and transformed, "from a teacher directed enterprise towards student-centered models" (Kaur \& Nanak, 2015, para. 5). Use of ICTs is made possible when the infrastructure is in place. These are network infrastructure, computing infrastructure, application software, Internet service, security infrastructure and policy document (Rao, 2009). The success of ICTs also depends on availability, accessibility, acceptability and adaptability (Robinson, 2008). Online learning is also guaranteed in third generation distance education (Bates, 2005). In developing countries such as Zimbabwe, ICTs are not fully utilised as most ODL institutions rely on print medium (UNESCO, 2014). Zimbabwe does not have a dedicated specific national policy on ICTs in education (Isaacs, 2007; Kungeni, 2017).

\subsubsection{Rationale for Using ICTs}

Most ODL institutions have been using and still use print medium. Challenges associated with print medium are the long distances students have to travel to regional and study centres to get them, for not having adequate human resources and not having enough space to house books, journals and some equipment. Some tutors and counsellors have not received enough training while cultural barriers impact negatively on teaching and learning. Some learners are used to the traditional methods of learning, hence, find ODL a bit challenging (Ramanujam, 2012). 
Ramanujam posits that some of the problems encountered above can be solved through the use of ICTs which are meant to keep institutions abreast with what is happening worldwide. ICTs are fast in transmitting content and employ a variety of methods to suit different needs and preferences of learners. ICTs facilitate easy access and feedback. ICTs enhance quality in education, provide "new sources of knowledge", expand education as learning takes place anywhere and at any time, “... 24 hours a day, seven days a week" and students can choose from many resources on the Internet (Shan Fu, 2013, p. 112). There are so many possibilities for instructors and learners (Shan Fu, 2013). ICTs through the World Wide Web promote a knowledge based industry where "educational systems ... create educational products and services that can be marketed internationally ... produce technology savvy graduates, able to use new technologies in the new economy" (Bates, 2005, p. 10). ICTs are in distance education, therefore, can be considered for economic and competitive lifelong learning, social equity and access, cost effectiveness and to reach out people in different geographical areas. They also promote commercialisation of education as for example, private companies and major universities in the US invest heavily on "online education businesses" (Bates, 2005, p. 12).

\subsubsection{Things to Consider When Using ICTs}

Education through ICTs cannot take place without connectivity. Connectivity means there is no distance among nations as materials can be shared. Rumanyika and Galan (2015) find lack of connectivity to be a barrier on use of ICTS in Tanzania. Institutions need to think of ways of putting into place, the infrastructure, ways of maintaining it and improving upon it. Lwoga (2012) is of the opinion that, because the above has not been put into place, it still poses a challenge to education in Tanzania. Governments must invest in ICTs while educationists should have a mindset that welcomes use of ICTs. "If the encouragement, equipment, and necessary technological support are available from institutes for the teachers, developing an ICT class will be easier for them" (Shan Fu, 2013, p. 114). In selection of suitable materials, students should be involved as they "discover learning topics, solve problems, provide solutions to problems in the learning process" (Shan Fu, p. 113). These can be offered through ICTs on a large scale and in a cost effective manner in subjects such as science and engineering where there are not enough teachers worldwide. This is reiterated by Christie, Jaun and Jonsson (2002, p. 3) who see the possibility of engineering students becoming lifelong learners through ICTs as it is perceived to be cheap, open and flexible for those "who need to upgrade knowledge and learn new skills" Students can be given educational tablets, so they engage in e-learning and can join the virtual classroom. This is supported by Li, Pow and Wong (2010) who propose the use of Tablet PCs.

To ensure success in the use of ICTs, issues of pedagogy which include quality content as well as decisionmaking must be put in place. Use of ICTs includes a whole range including the Internet, radio, telephone, satellite, so, it is important for each institution to choose the best option for the needs of different students. Rajesh (2003, p. 10) is concerned with "pedagogic value" as it is one of the factors to take cognizance of ICT adoption. "Transferring a badly designed, badly written and badly assessed course to the Internet does not make it pedagogically better" (Christie et al., 2002, p. 3). For developing countries, objectives for the use of ICTs should be well defined to teachers and media specialists, who in turn, should be trained. According to Christie et al. (2002, p. 3), "a poorly trained or retrained person could cost more money than what it saves on running an in-house course". For them, a substandard ICT course might culminate into having a "false economy". Planning and implementation should be done and the institutional policy be 
well articulated (Kungeni, 2017). This is supported by UNESCO (2009 as cited in Rumanyika and Galan, 2014) that it is not ideal to introduce ICTs that are not suitable to students' and faculty needs and that they should not be imposed from the top down. Further, they should not be taken from other nations without customising them. Finally, the graduates who use ICTs should be assessed to see whether or not they will compete on the job market (Ramanujam, 2012).

\subsubsection{Challenges Related to ICTs in Developing Countries}

dela Pena-Bandalaria (2007) realises the challenges that ODL institutions in developing countries face with regard to ICTs. One of them is digital divide where most people do not have access to ICTs as some of these countries concentrate more on providing food, shelter and clothing such that adoption of ICTs seems unthinkable. Digital divide is "the gap between the students who have access to the digital technology at home and those who do not" (Mason \& Dodds, 2005a; 2005b as cited in Chi-Yuan Sun \& Metros, 2011, p. 154). Digital divide is affected by "socio-economic status, ethnicity and geographic location" (p. 154). Poor countries have to grapple with problems of debt, disease and ignorance and may fail to match with those whose ICT infrastructure in the area of provision of ICTs is high (Norris, 2001, p. 5 as cited in Graham, 2011). In Zimbabwe, with a population of about 13061239 in 2012 (Machadu, 2013), the number of Internet users as in 2013 was 5.2 million people which is $39.8 \%$ of the population (The Postal Telecommunications Regulatory Authority of Zimbabwe, 2015). Despite this increase, still quite a large percentage of people do not have access to the Internet. In adopting ICTs in ODL, the kind of ICTs to be used have to be taken into consideration. This means adoption of new cultures, concepts and new methods of teaching and learning (dela Pena-Bandalaria, 2007) which should, however, be based on sound pedagogic principles (Ramanujam, 2012).

Fox (2012) observed that in Zimbabwe most people access Internet at cybercafés or at work in Harare which is mostly dial-up than broadband. Most Zimbabweans do not earn much, therefore; cannot afford to buy a modem, computer or fees that are paid for Internet services. Further, Zimbabwe has not been able to meet the deadline of 17 June 2015 for digitalisation set out by International Telecoms Union (ITU) in 2006 where all countries are supposed to switch from analogue to digital (Charumbira \& Samukange, 2015). Other challenges related to ICT adoption are policy makers not promoting ICTs due to their perceptions and attitudes (Kungeni, 2017; Rajesh, 2003). Also, the infrastructure is not appropriate due to inadequate resources, and hence, maintenance of the equipment becomes impossible, expensive Internet connectivity that hinders many people from accessing the Internet, cultural factors that might make it difficult to adopt educational content from other cultures and not having trained personnel to handle ICTs (Rajesh, 2003).

\section{Methodology}

The researcher used a qualitative research as this was found to be suitable for a case study. In this study, the researcher involved ZOU staff members and students' feelings, attitudes and some issues that could not be quantified or generalised. The research methods used were interviews and open-ended questionnaires from ZOU staff members and students. Purposive and convenience sampling were used on ZOU staff members and students. 


\subsubsection{Design}

The research design used was that of a case study of ZOU since the institution offers teaching and learning through ODL and the researcher wanted some in-depth information on the use of ICTs in teaching and learning.

\subsubsection{Data Collection}

Data was collected personally from ZOU staff in Harare and from ZOU students at Harare/Chitungwiza Campus.

\subsubsection{Participants}

Nine participants chosen by the researcher composed one virtual region personnel, one LIS official, a ZOU webmaster, three lecturers and three students.

\section{Results}

From the findings of the use of ICTs through interviews, (Interview, Virtual Region Personnel; 17 June, 2019), it was established that Zimbabwe Open University utilised ICTs in the Virtual Region with ZOU students studying in other countries, in the region or international arena. Some of these students, were at the University of Zambia. Other students were scattered everywhere, in the United Kingdom, Saudi Arabia, France, South Africa, Namibia, Sierra Leone, Nigeria and many others. ICTs play a big role in that such students were not bound by time and distance; they communicated with the institution through e-mail, Smart phones and Skype. The Virtual offices were paperless; registration, offering of places, payment of fees, and issuing of modules were done online. The education offered was cost effective to the students as they did not have to travel, thus, they saved on air fares. Examinations, which are set by the institution are written in the countries where the students are. For students doing dissertations, follow up of supervisors is done by the institution. To note is the fact that print medium is used to complement soft copies as some students work in places where ICTs cannot be accessed.

Challenges encountered were that some lecturers and students were reluctant to fully utilise ICTs. Aggressive marketing of the Region and the products offered were being hampered by the overall bleak economic outlook in Zimbabwe. Marketing, which involves advertising, travelling to different cities was expensive. The Region hoped to establish partnerships with other universities so the latter could assist in marketing and recruitment of students.

From the findings, all ZOU students had cellular phones and that, with provision of tablets to students, multimedia delivery would be made possible. It was recommended that there should be an initiation of policy changes that would support the use of ICTs more since to date there was little evidence of innovation. ZOU was advised to look into the use of technology integration in teaching and learning and find out how well prepared it was. Mobile learning is an interesting area to students which could be looked into from the perspectives of students. Blogs could be created and made use of as well as Facebook for teaching purposes. Multimedia technology could enrich teaching and learning, complement modules, 
attract more learners and thus, can make learning more exciting. ZOU, as an institution, embraced the idea of ICTs, what it needed to do was to translate this into a policy.

The second interview was with (LIS, official, 17 June, 2019). He said, the infrastructure for online learning had been set up and the Internet was $98 \%$ reliable. Students could access the library through online databases - ebrary, e-books, e-journals and could be assisted on pedagogical issues (information from the ZOU Library and Service Information System).

Another interview was done with the ZOU Webmaster (8 July, 2019) who said the role of the ICT Department was to provide technical support. The ICT Department enabled students to apply and register online through the ZOU website. It also had backup data for these students, such as bio-data, certificates in PDF, invoices, accounts statements and any other documents. Students could download modules online and were provided with additional content by their lecturers. ICTs enabled all registered ZOU students to have access to ICTs ... MyVista.

Information was also obtained from three lecturers on use of ICTs in teaching and learning at ZOU. One lecturer said that educational content, such as OERs could only be utilised with the knowledge of ICTs. Another lecturer said that content, through ICTs and the Internet, could be obtained in different environments and these could not only be produced, but printed as well. The third participant said ICTs were used by lecturers and students to access the ZOU platform, MyVista. ICTs were used to gather data and to ensure that information got to the intended recipients fast.

Challenges identified by the lecturers were that of connectivity as it was too expensive for them to access the Internet in their homes. At the workplace, the bandwidth was limited as well as the hardware and the software. Power outages were identified as another challenge. Another concern was that of lecturers and students who were not computer literate.

Students also expressed their opinions with regard to ICTs, in learning. One participant said that educational content from all over the world could be obtained easily through the Internet. The second student said that ICTs enabled people to produce, manipulate, access and share educational content. The third participant said ICTs enhanced her studies. Another challenge cited by the participants was that the Internet was slow and hence, could not be relied upon. Funding challenges, not having enough time to surf the Internet and lack of connectivity were also cited. Some students did not have computers and the knowledge and skills in the use of ICTs. Lecturers and students cited similar limitations in the use of ICTs, such as that it cost a lot of money to go online, power outages, limited bandwidth, problems or hardware and software and lack of computer skills.

\section{Discussion}

An interesting finding from the participants was, ZOU, through use of ICTs could become paperless, thus, reducing the costs of printing modules. This is supported by Arinto (2013) who has witnessed the University of Philippines - Open University (UPOU) becoming resource-based and moving away from print as the university welcomes OERs. The university is also moving from ODL to open and distance elearning (ODeL). Also, ICTs enable ZOU to reach students from all over the world and ZOU staff to avail and mark assignments online. However, lack of ICT skills, connectivity and too many students using few 
computers in regional campuses hinder full utilisation of ICTs by ODL students at ZOU (Mafa \& Mpofu, 2013). What ZOU lecturers and students brought to the surface was contrary to what the Library official had said that the Internet infrastructure was $98 \%$ ready. The differences could emanate from the fact that the pinch was felt more by the former, who were the end users than the latter. Another finding, that students could be reached through email and smartphones is reinforced by dela Pena-Bandalaria (2007) who brings out the fact that mobile phones can be used effectively by many Filipino students, thus, narrowing the digital divide while learning becomes cheaper. However, mobile phones have limitations due to the fact that they can contain limited information.

Second, the ZOU library has e-resources that ZOU staff and students could make use of. However, I feel that training should be conducted for all on how to use ICTs, the Internet and these resources. Another challenge would be for ZOU staff and students in remote areas that cannot access the Internet. This is coupled with some ZOU staff and students not willing to use ICTs, hence, use of print cannot be totally avoided.

Arinto (2013, p. 178) in her study points out challenges encountered by teachers in web-based learning. Web-based learning has challenges of too many resources which makes it difficult for teachers to choose suitable learning materials let alone getting the time to choose those materials. Further, the learning content might have cultural implications such that it might not be suitable for the Philippine context. Giving guidance to the learner is difficult so as "ensuring equity and fairness in assessment ... meet the same standards of quality and enable learning to the same degree".

Another area was that of ZOU staff and students being able to produce, manipulate and share educational content worldwide through ICTs. This can be made possible through OERs that can be shared and repurposed to suit different environments (Wiley, Bliss, \& McEwen, 2014). Smith and Casserly (2006, p. 10) repeat the same sentiments when they say OERs have been enabled by technology and World Wide Web to provide opportunities to everyone "to share, use, and reuse that knowledge."

Some students mentioned that they did not have computers. The implication of this is digital divide where those without the resources might not be able to have access to ICTs and to surf the Internet. Socioeconomic status and geographical location are regarded as some of the reasons that contribute to digital divide (Chi-Yuan Sun, \& Metros, 2011). Mafa and Mpofu (2013) in their study on ODL students concur with the above findings in that some students were not able to buy computers and laptops due to limited finances since most of them were civil servants who did not earn much and thus, gave priority to their dependents, that is, their children and others.

\section{Conclusion}

ICTs facilitate uploading of modules which are downloaded by the students in different parts of the world through MyVista. ICTs enable the students to apply and register online, to access invoices, accounts statements online, sending assignments for marking online and obtaining marked assignments and results. It becomes imperative that ICTs, especially in ODL institutions in developing countries should create some forums where students communicate with each other through video conferencing, blogs, Facebook, Twitter and many other social networks. Also, ODL institutions should fully articulate policies that support use of ICTs in teaching and learning. Universities in developing countries should increase the bandwidth 
and upgrade internet connectivity and avail money for the hardware and software so all the users do not get frustrated when accessing ICTs. They should look for ICTs that are relevant, seek partnerships and collaborations with other institutions, how to implement and evaluate them (dela Pena-Bandalaria, 2007). Finally, ODL institutions should facilitate training of staff and students in the use of ICTs so they can fully utilise educational content including OERs and MOOCs.

\section{References}

Arinto, P. B. 2013). A framework for developing competencies in open and distance learning. International Review of Research in Open and Distance Learning, 4(1), 167-185 doi.org/10.19173/irrodl.v14i1.1393.

Awadhiya, A. K., Miglani, A., \& Gowthaman, K. (2014). ICT usage by distance learners in India. Turkish Online Journal of Distance Education (TOJDE), 15(3), 242-253.

Bates, A. W. (2005). Technology, e-learning and distance education ( $2^{\text {nd }}$ ed.). London: Routledge.

Charumbira, S., \& Samukange, T. (2015). Zimbabwe misses digitalisation target. National News, 17 June, 2015.

Chi-Yuan Sun, J., \& Metros, S. E. (2011). The digital divide and its impact on academic performance. US-China Review A, 2(2011), 153-161.

Christie, M., Jaun, A., \& Jonsson, L. E. (2002). Evaluating the use of ICT in engineering education. European Journal of Engineering, 27(1), 13-20.

dela Pena-Bandalaria, M. (2007). Impact of ICTs on distance and open learning in a developing country setting: The Philippine experience. IRRODL, $8(1)$.

Fox, C. (2012). Zimbabwe pushes for open education despite oppression. Retrieved from

file:///K:/Zimbabwe\%20ranked\%20one $\% 20$ of\%20worst $\% 20$ countries $\% 20$ for $\% 20$ national $\% 20$ information\%20communication\%20technology\%20_\%20Opensource.com.htm

Graham, M. (2011). Time machines and virtual portals: The spatialities of the digital divide. Progress in Development Studies. Retrieved from https://journals.sagepub.com/doi/pdf/10.1177/146499341001100303

Kaur, N., \& Nanak, G. (2015). Using ICT in empowering teachers for quality education. International Journal of Scientific Research Engineering \& Technology LISRET), ISSN: 2278-0882. EATHD-2015 Conference Proceeding, 14-15 March 2015.

Isaacs, S. (2009). ICT in education in Zimbabwe. Retrieved from https://www.infodev.org/infodevfiles/resource/InfodevDocuments_437.pdf 23,10/19.

Kungeni, P. (2017). An investigation into the challenges that are being faced in the use and teaching of computers in schools: A case of six secondary schools in Chihota district Mashonaland East Province, for period (2012-2017). A research project submitted to the Midlands State University in partial fulfillment of the requirements of the degree in adult education programme, Gweru, Zimbabwe.

Li, S. C., Pow, J. W. C., Wong, E. M. L. (2010). Empowering student learning through Tablet PCs: A case study. Education and Information Technologies, 15(3), 171-180. https:/doi.org/10.1007/s10639-009-91032-2

Lwoga, E. (2012). Making learning and Web 2.0 technologies work for higher learning institutions in Africa. Campus-Wide Information Systems, 29(2), 90-107.

Machadu, C. (2013). ZIMSTAT releases final census results. The Zimbabwean.

Mafa, O., \& Mpofu, J. (2013). The extent to which open and distance learning students utilize information and communication technology in their assignments and research projects. IOSR Journal of Research and Method in Education (IOSR-JRME), 1(4), 33-39. 
Mishra, A. (2015). Enabling the role of ICTs in distance education programs EdTechReview, http://edtechreview.in/trends-insights/insights/1807-enabling-the-role-of-ict-in-distancelearning-education-programs.

Rajesh, M. (2003). A study of the problems associated with ICT adaptability in developing countries in the context of distance education. Turkish Journal of Distance Education-TOJDE, 4(2), 1-10.

Ramanujam, P.R. (2002). Overcoming barriers to access and success: Some strategic issues. Retrieved from http://www.col.org/pcf2/papers\%5Cramanujam.pdf

Rao, M. M. (2009). ICT in open distance learning: Issues and challenges. Retrieved from www.col.org/pcf6/2/IN4327.doc

Robinson, B. (2008). Using distance education and ICT to improve access, equity and quality in rural teachers' professional development in Western China. IRRODL, 9(1), 1-17.

Rumanyika, J. D., \& Galan, R. M. (2015). Challenges for teaching and learning information and communication technology courses in higher learning institutions in Tanzania: A review. Information Knowledge Management, 5(2).

Shan Fu, J. (2013). ICT in education: A critical literature review and its implications. International Journal of Education and Development using Communication and Information Technology (IJEDICT), 9(1), 112-125.

Smith, M., \& Casserly, 2006). The promise of open educational resources. Change: The Magazine of Higher Learning. Retrieved from http://www.icde.org/the+Promise+of+OER.9uFRzIXH.ips

TechZim (2015). Zimbabwe Internet statistics: 5.2 million subscriptions. $40 \%$ penetration. Retrieved from http://www.techzim.co.zw/2014/01/zimbabwe-internet-statistics-5-2-millionsubscriptions-40-penetration/

Wiley, D., Bliss, T. J., \& McEwen, M. (2014). Open educational resources: A review for the literature. In J. M. Spector, M. D. Merrill, J. Elen, \& M. J. Bishop (Eds.), Handbook of research on education communications and technology. (781-789). New York: Springer.

Zuppo, C. M. (2012). Defining ICT in a boundaryless world: The development of a working hierarchy. International Journal of Managing Information Technology, 4(3), 13-22. 